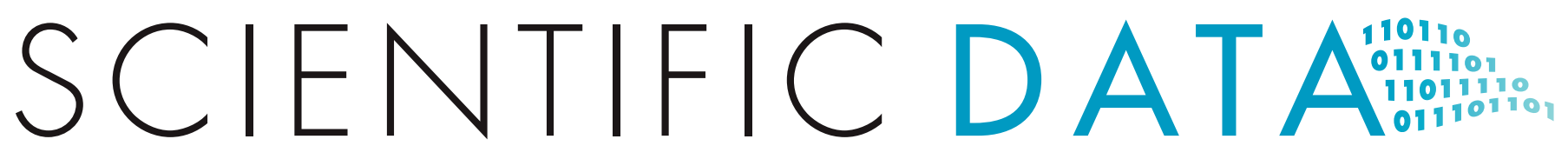

OPEN Corrigendum: The Centennial

\title{
Trends Greater Horn of Africa precipitation dataset
}

Chris Funk, Sharon E. Nicholson, Martin Landsfeld, Douglas Klotter, Pete Peterson \& Laura Harrison

Scientific Data 2:150050 doi: 10.1038/sdata.2015.50 (2015); Published 29 September 2015; Updated 3 July 2018.

Panels a-e were accidentally omitted from Figure 2. A complete version of this figure has been provided below. 

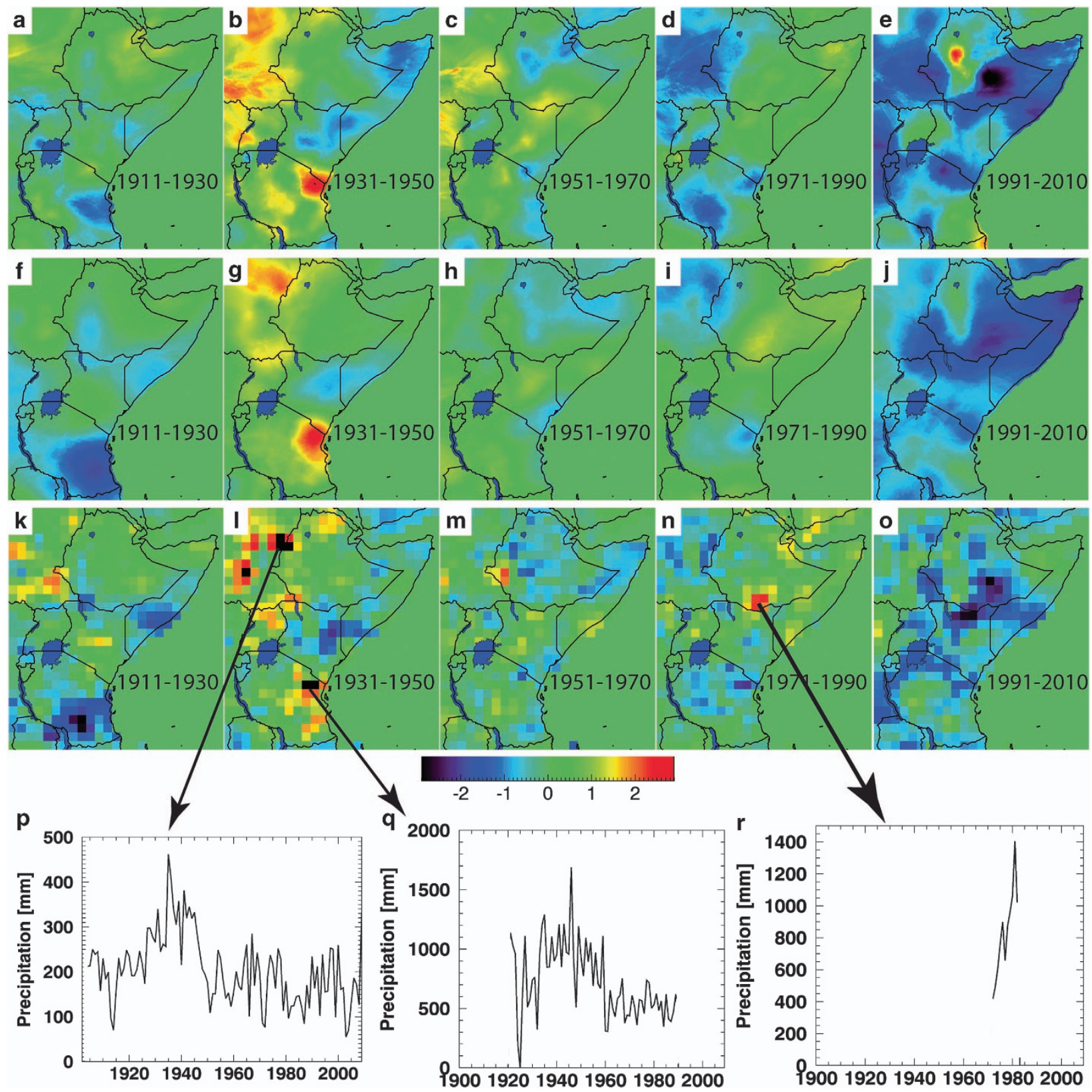

Figure 1.

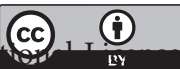

Open Access This article is licensed under a Creative Commons Attribution 4.0 Internawhich permits use, sharing, adaptation, distribution and reproduction in any medium or format, as long as you give appropriate credit to the original author(s) and the source, provide a link to the Creative Commons license, and indicate if changes were made. The images or other third party material in this article are included in the article's Creative Commons license, unless indicated otherwise in a credit line to the material. If material is not included in the article's Creative Commons license and your intended use is not permitted by statutory regulation or exceeds the permitted use, you will need to obtain permission directly from the copyright holder. To view a copy of this license, visit http://creativecommons. org/licenses/by/4.0/

(c) The Author(s) 2018 